\title{
Species composition of hard ticks (Acari: Ixodidae) on domestic animals and their public health importance in Tamil Nadu, South India
}

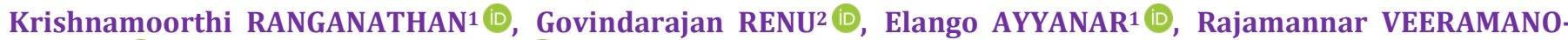 \\ HARAN $^{2}$ (D), Philip Samuel PAULRAJ ${ }^{2,3}$ (i)
}

${ }^{1}$ ICMR-Vector Control Research Centre, Puducherry, India

${ }_{2}^{2}$ ICMR-Vector Control Research Centre Field Station, Madurai, Tamil Nadu, India

${ }^{3}$ Corresponding author: philipsamuelpaulraj@gmail.com

\begin{abstract}
This study was carried out in Madurai district, Tamil Nadu State, South India. Ticks were collected from cows, dogs, goats, cats and fowls. The overall percentage of tick infestation in these domestic animals was $21.90 \%$. The following ticks were identified: Amblyomma integrum, Haemaphysalis bispinosa, Haemaphysalis paraturturis, Haemaphysalis turturis, Haemaphysalis intermedia, Haemaphysalis spinigera, Hyalomma anatolicum, Hyalomma brevipunctata, Hyalomma kumari, Rhipicephalus turanicus, Rhipicephalus haemaphysaloides and Rhipicephalus sanguineus. The predominant species recorded from these areas is R. sanguineus $(27.03 \%)$ followed by both $R(B$.$) microplus (24.12\%) and R$. (B.) decoloratus (18.82\%). The maximum tick infestation rate was recorded in animals from rural areas (25.67\%), followed by semi-urban $(21.66 \%)$ and urban $(16.05 \%)$ areas. This study proved the predominance of hard ticks as parasites on domestic animals and will help the public health personnel to understand the ground-level situation and to take up necessary control measures to prevent tick-borne diseases.
\end{abstract}

Keywords: Ticks, domestic animals, Ixodidae, prevalence.

Zoobank: http://zoobank.org/D8825743-B884-42E4-B369-1F16183354C9

\section{INTRODUCTION}

Hard ticks (Acari: Ixodidae) are involved in the transmission of a variety of disease pathogens of public health and veterinary importance (Arthur, 1962; Estrada-Pena and Jongejan, 1999; Parola and Raoult, 2001; Barandika et al., 2007; Brites-Neto et al., 2015; Liyannaarachchi et al., 2015; Tonetti et al., 2020). Today, the order Ixodida includes 970 species of ticks known all over the world which are included in four families, being three extant Ixodidae (750 spp.), Argasidae (218 spp.), one Nuttalliellidae and one extinct Deinocrotonidae (Guglielmone et al., 2015; Dantas-Torres et al., 2019). In India, domestic animals are often infested heavily with multi-species of ticks transmitting different diseases such as theileriosis, babesiosis, and anaplasmosis (Ghosh and Nagar, 2014). Tick studies gained much significance after the Shimoga district of Karnataka state, reported Kyasanur Forest Disease (KFD) transmitted by Haemaphysalis spp. (Pattnaik, 2006). Crimean-Congo hemorrhagic fever (CCHFV) virus infection in domestic animals and humans were reported from different parts of the country (Shanmugan et al., 1976). So far in Madurai district, no tick surveillance was undertaken and no data is available about the distribution pattern of the ticks. Hence this study was undertaken to study the available tick species and to know about the prevalence of different vector species in Madurai district.

\section{MATERIALS AND METHODS}

Madurai district situated in the Tamil Nadu state of India is one of the 38 districts in the Tamil Nadu state. The latitude of Madurai, Tamil Nadu, India is $9.9533^{\circ} \mathrm{N}$ and the longitude is $78.0195^{\circ} \mathrm{E}$. The geographical area of this district is $147.97 \mathrm{~km}^{2}$. The total population as per the 2011 census is $1,470,755$. The average annual minimum temperature in Madurai is $23.9^{\circ} \mathrm{C}$, the average maximum is $34.5{ }^{\circ} \mathrm{C}$, and the annual rainfall is $869.4 \mathrm{~mm}(34.23$ inch). The study area of Madurai was grouped into three regions viz. urban, semi-urban, and rural environmentals (Fig. 1). In each habitat, 100 households were selected randomly. This study incorporated different household animals like cows, dogs, goats, cats and fowls. Ticks were collected with fine-tipped tweezers and kept separately for identification in sample vial containing 70\% ethanol, location, host, and date of collection was noted. Ticks were identified using the available tick identification keys (Sharif, 1928; Geevarghese and Dhanda, 1987; Walker et al., 2003; Geevargheese and Mishra, 2011). Immature ticks were mounted with Hoyer's medium (Prakasan and Ramani, 2007). All collected specimens were deposited in Mosquito/Ectoparasite Museum, Entomology Laboratory of ICMR-Vector Control Research Centre Field Station, Tamil Nadu, India. The tick index and the tick infestation rate were calculated. The data analysis was performed using SPSS Ver. 15 (Statistics Package for Social Sciences).

\section{RESULTS}

This study showed the presence of ticks on 1,224 household animals cows (417), dogs (153), goats (465), cats (19), and fowl (170) belonged to 14 species and 5 genera. The following ticks wereidentified: Amblyomma integrum Karsch, 1879, Haemaphysalis bispinosa, Newmann, 1897, Haemaphysalis paraturturis Hoogstraal, Trapido and Rebello, 1963, Haemaphysalis turturis Nuttall and 


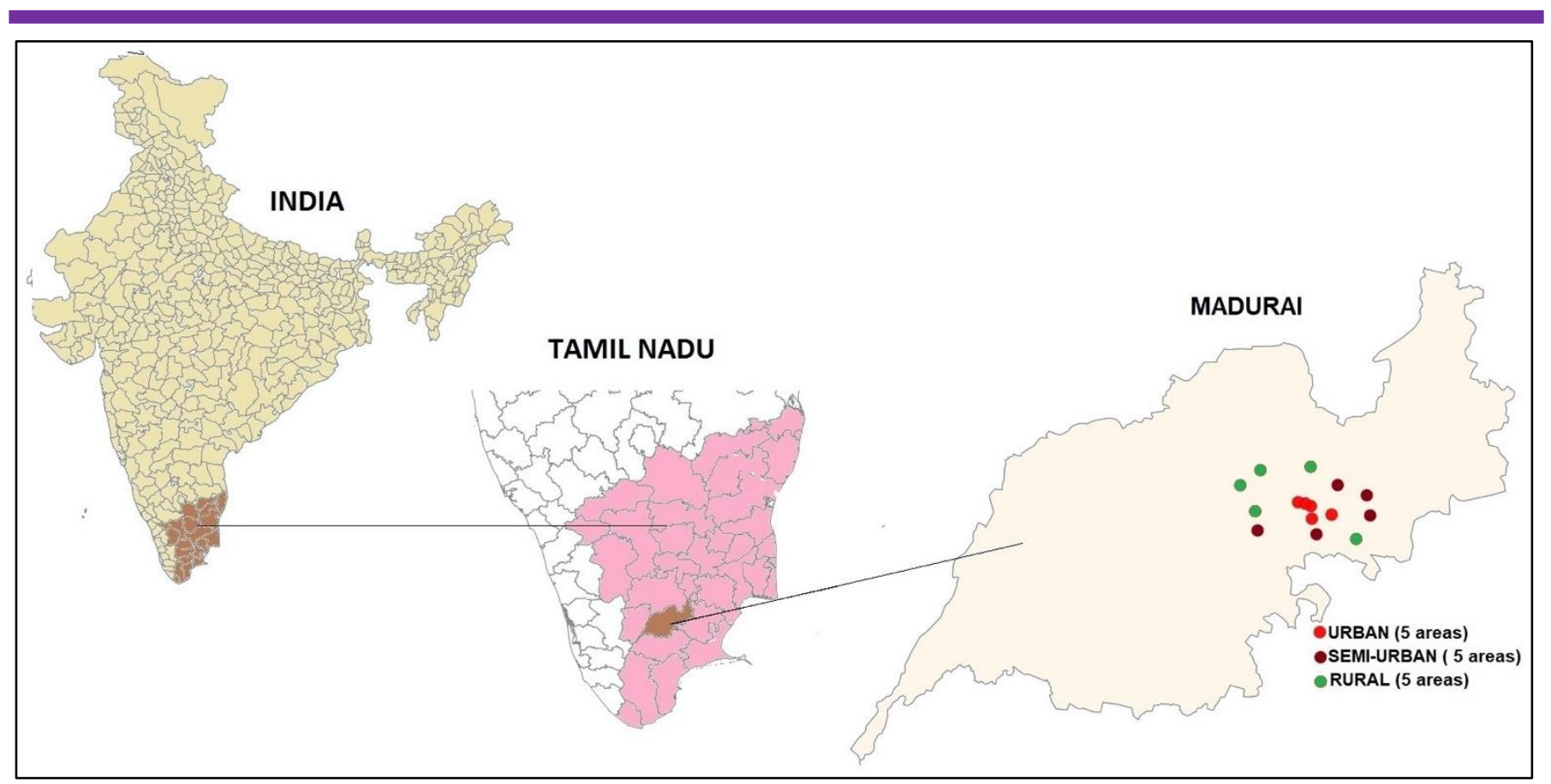

Figure 1. Localities where the field work was carried out in Madurai district.

Warburton, 1915, Haemaphysalis intermedia Warburton and Nuttall, 1909, Haemaphysalis spinigera Neumann, 1897, Hyalomma anatolicum (Koch, 1844), Hyalomma brevipunctata Sharif, 1928, Hyalomma kumari Sharif, 1928, Rhipicephalus (Boophilus) annulatus (Say, 1821), Rhipicephalus (B.) decoloratus (Koch, 1844), Rhipicephalus (B.) microplus (Canestrini, 1887), Rhipicephalus turanicus Pomerantzev, 1940, Rhipicephalus haemaphysaloides Supino, 1897, and Rhipicephalus sanguineus complex (Latrielle 1806) (Table 1). A list of 15 tick species collected in this study and the detailed gender and life stage is shown in Table 1.

Prevalence and infestation details of tick species in domestic animals is furnished in Table 1 and 2 . Among the three localities, the maximum collection was recorded from semi-urban areas. The total tick infestation rate was calculated to be $21.90 \%$ and the tick index was 0.922 . In the rural areas 13 species of ticks were found, followed by 11 species of ticks recorded from semi-urban areas and eight from urban areas. The rural habitat showed a maximum number of tick species. The predominant species recorded from these areas was $R$. sanguineus complex (27.03\%), followed by both $R$. (B.) microplus and $R$. (B.) decoloratus $(24.12 \%$ and $18.82 \%)$, respectively. The maximum number of ticks were collected from cows $(41.43 \%$ of the ticks), followed by dogs (18.02\%), goats $(36.92 \%)$, cats $(1.59 \%)$ and fowls $(2.03 \%)$. Tick abundance rate concerning different host animals was $27.33 \%$ for cows, $22.88 \%$ for dogs, $19.35 \%$ for goats, $36.84 \%$ for cats, and $12.94 \%$ for fowl (Table 2). Ticks were collected mostly from ears followed by neck and udder of the animals. A list of 10 medically important tick vectors collected in this study is shown in Table 3.

There was a significant difference in the distribution of ticks among rural, semi-urban, and urban localities (F5.465 , df-2, $\mathrm{p}<0.05)$. Again there was a significant difference in the distribution of ticks among the five host ani- mal groups (F-4.938, df-4, p<0.05). Finally, cross-analysis of three localities versus 5 host (15 species of ticks) showed a significant difference among the tick positivity (F-3.287, df-14, p<0.05).

\section{DISCUSSION}

The first major contribution to Indian tick fauna was by Sharif (1928), who reported 45 species of ticks preserved in the Zoological Survey of India (Indian Museum in Calcutta. Sen (1938) prepared a check-list for 50 species of Ixodid ticks found on the domestic stock. A check-list of different tick species on various vertebrate hosts and from many areas of the country was prepared by the National Institute of Virology in Pune (Geevarghese et al., 1997; Geevargheese and Mishra, 2011). In India, so far 109 tick species were reported of which 88 belong to the family Ixodidae (Geevarghese et al., 1997; Ghosh et al., 2007). Tick faunal studies from the eastern Himalayas recorded 14 different species of ixodid ticks belonging to seven genera with an abundant collection of Amblyomma spp. and R. (B.) microplus (Varma and Mahadevan, 1970). In Jammu and Kashmir 16 different species of ixodid ticks belonging to seven genera were recorded (Kaul et al., 1990). Ixodid ticks belonging to seven genera and 17 species were collected from North-East Frontier Agency, India (Dhanda and Ramachandrarao, 1964).

In Haryana, six different tick species from three genera of hard ticks were collected (Chhilar et al., 2014). A study conducted in Karnataka reported hard ticks infesting sheep and goats (Jagannath and Lokesh, 1988; Saxena, 1997). Kumar et al. (2002) reported the presence of hard ticks in Tamil Nadu. Similarly in Kerala Prakasan and Ramani (2003) reported hard ticks infestation in humans. The presence of hard ticks in different domestic animals was already reported from many states like Karnataka, Tamil Nadu and Assam (Jagannah et al., 1979; Latha et al., 2004; Miranpuri and Singh, 1978). Saxana et al. (1984) reported eight different species of ticks, and Kumar et al. 
Table 1. Prevalence of tick species in domestic animals in Madurai, Tamil Nadu, India.

\begin{tabular}{|c|c|c|c|c|c|c|c|c|c|c|}
\hline \multicolumn{2}{|c|}{ Family Genus } & Species & Nymph & $\%$ & Male & $\%$ & Female & $\%$ & Total & $\%$ \\
\hline \multirow{15}{*}{ 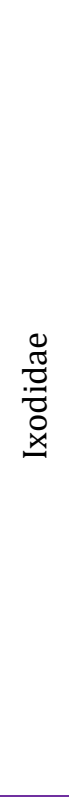 } & Amblyomma & Amblyomma integrum & 3 & 0.27 & 1 & 0.09 & 10 & 0.88 & 14 & 1.24 \\
\hline & \multirow{5}{*}{ Haemaphysalis } & Haemaphysalis bispinosa & 8 & 0.71 & 14 & 1.24 & 75 & 6.63 & 97 & 8.57 \\
\hline & & Haemaphysalis paraturturis & 0 & 0.00 & 0 & 0.00 & 9 & 0.80 & 9 & 0.80 \\
\hline & & Haemaphysalis turturis & 8 & 0.71 & 2 & 0.18 & 21 & 1.86 & 31 & 2.74 \\
\hline & & Haemaphysalis intermedia & 7 & 0.62 & 12 & 1.06 & 34 & 3.00 & 53 & 4.68 \\
\hline & & Haemaphysalis spinigera & 0 & 0.00 & 2 & 0.18 & 14 & 1.24 & 16 & 1.41 \\
\hline & \multirow{3}{*}{ Hyalomma } & Hyalomma anatolicum & 0 & 0.00 & 0 & 0.00 & 12 & 1.06 & 12 & 1.06 \\
\hline & & Hyalomma brevipunctata & 2 & 0.18 & 0 & 0.00 & 9 & 0.80 & 11 & 0.97 \\
\hline & & Hyalomma kumari & 3 & 0.27 & 9 & 0.80 & 20 & 1.77 & 32 & 2.83 \\
\hline & \multirow{6}{*}{ Rhipicephalus } & Rhipicephalus (B.) annulatus & 3 & 0.27 & 0 & 0.00 & 14 & 1.24 & 17 & 1.50 \\
\hline & & Rhipicephalus (B.) decoloratus & 4 & 0.35 & 42 & 3.71 & 167 & 14.75 & 213 & 18.82 \\
\hline & & Rhipicephalus (B.) microplus & 1 & 0.09 & 84 & 7.42 & 188 & 16.61 & 273 & 24.12 \\
\hline & & Rhipicephalus turanicus & 2 & 0.18 & 11 & 0.97 & 26 & 2.30 & 39 & 3.45 \\
\hline & & Rhipicephalus haemaphysaloides & 0 & 0.00 & 2 & 0.18 & 7 & 0.62 & 9 & 0.80 \\
\hline & & Rhipicephalus sanguineus & 17 & 1.50 & 116 & 10.25 & 173 & 15.28 & 306 & 27.03 \\
\hline & & Total & 58 & 5.12 & 295 & 26.06 & 779 & 68.82 & 1132 & 100 \\
\hline
\end{tabular}

Table 2. Tick infestation rate and tick index in study areas.

\begin{tabular}{cccccc}
\hline Host & Total host examined & Host infested & Total ticks collected & Infestation (\%) & Tick index \\
\hline Cow & 417 & 114 & 469 & 27.34 & 22.88 \\
Dog & 153 & 35 & 204 & 19.35 & 1.33 \\
Goat & 465 & 90 & 418 & 36.84 & 0.90 \\
Cat & 19 & 7 & 18 & 12.94 & 0.95 \\
Fowl & 170 & 22 & 23 & 21.90 & 0.14 \\
\hline Total & 1,224 & 268 & 1,132 & 0.92 \\
\hline
\end{tabular}

Table 3. List of medically important tick vectors collected in this study.

\begin{tabular}{|c|c|c|c|c|}
\hline No & Vector & Disease & Parasite/pathogens & $\mathrm{R}$ \\
\hline 1 & Amblyomma integrum & Otoacariasis & Otalgia & $\mathrm{R} 1$ \\
\hline 2 & Haemaphysalis intermedia & Ganjam virus & Nairobi sheep disease & R3 \\
\hline 3 & Haemaphysalis spinigera & Kyasanur Forest disease & $\begin{array}{l}\text { Group B Toganvirus (Fla- } \\
\text { vidiridae) }\end{array}$ & $\mathrm{R} 2$ \\
\hline 4 & Haemaphysalis turturis & Kyasanur Forest disease & KFD virus & $\mathrm{R} 2$ \\
\hline 5 & Hyalomma anatolicum & Crimean-Congo haemorragic fever & Babesia equi & $\mathrm{R} 2$ \\
\hline 6 & Rhipicephalus (B.) annulatus & Babesiosis & Babesia sp. & $\mathrm{R} 2$ \\
\hline 7 & Rhipicephalus (B.) decoloratus & Indian tick typhus & Rickettsia conorii & $\mathrm{R} 2$ \\
\hline 8 & Rhipicephalus (B.) microplus & Babesiosis & Babesia bigemina, B. ovis & $\mathrm{R} 2$ \\
\hline 9 & Rhipicephalus sanguineus & Indian tick typhus, ehrlichiosis & $\begin{array}{l}\text { Rickettsia conorii, Ehrlichia } \\
\text { canis, E. equi }\end{array}$ & $\mathrm{R} 2$ \\
\hline 10 & Rhipicephalus turanicus & Rickettsial disease & Coxiella, Rickettsia & $\mathrm{R} 4$ \\
\hline
\end{tabular}

R-References: R1-Bandaranayaka et al. (2016), R2-Ghosh and Nagar (2014), R3-Geevarghese and Mishra (2011), R4Chochlakis et al. (2014).

(2014) reported 12 species of ticks on different domestic animals in Nilgiris hills situated in Tamil Nadu. A total of 14 species of ticks belonging to 5 genera infesting domestic animals in Villupuram district, Tamil Nadu were recorded Shobana et al. (2013). This study showed that more favourable conditions prevail in Madurai for the propaga- tion of haematophagous ticks with richness in vegetation and animal fauna with special reference to rural areas. Similarly to the observations of Shobana et al. (2013) also in this study cats had a minimum number of ticks. 
A study about the tick fauna in the Shimoga district of Karnataka showed the presence of $H$. spinigera on dogs which facilitate the maintenance of the Kyasanur Forest disease (KFD) virus (Kumar et al., 2008). In Shimla hills species like Hyalomma spp., $R$. sanguineus complex, $R$. haemaphysaloides, Haemaphysalis spp. and Ixodes spp. with their role in disease transmission (Mehta, 1937). The presence of Hyalomma species in the region confirms the presence of the CCHF virus in Gujarat (Gandhi et al., 2011). A large number of the species infesting the different livestock were recorded as vectors of different pathogens (Liyannaarachchi et al., 2015; Tonetti et al., 2020). Tick-borne diseases like KFD and CCHF are of public health importance and the KFD virus was isolated from tickssuch as $H$. spinigera, $H$. turturis, and $H$. bispinosa in India. This present study showed the prevalence of the different species of ticks and the pattern of infestation on different domestic animal hosts namely cows, goats, dogs, cats, and fowl. In this study we have also observed the presence of 10 species tick vectors and the disease they cause as shown in Table 2.

This study showed for the first time the species of ticks existing on livestock in the region of Madurai district. Further studies are required to understand the epidemiology of those ticks, their vectorial potential for pathogenic microorganisms as well as the seroprevalence of tickborne diseases in the human population. Tick control methods are to be adopted to keep the tick abundance in check at regular intervals to prevent the spread of tickborne diseases.

\section{Authors' contributions}

Krishnamoorthi Ranganathan: Collection of the specimens, processing of the specimens, identification and preservation. Govindarajan Renu: Collection of the specimens, processing of the specimens, identification, preservation, review and editing. Elango Ayyanar: Identification, verification, data curation. Rajamannar Veeramanoharan: Data analysis, visualization, software programming. Philip Samuel Paulraj: Conceptualization, supervision and project administration.

\section{Statement of ethics approval}

This study was approved by the Institutional Animal Ethics Committee (IAEC) of ICMT-Vector Control Research Centre, Puducherry.

\section{Funding}

This work was supported by the Indian Council of Medical Research (ICMR-VCRC/IM1710).

\section{Conflict of interest}

None of declare.

\section{Acknowledgment}

We are thankful to our Director, Dr. Ashwani Kumar, ICMR-VCRC, Puducherry, and the previous Director Dr. Jambulingam, ICMR-VCRC, Puducherry for providing all the necessary facilities, constant encouragement, guidance and useful suggestions for undertaking this study. We want to express our deep sense of gratitude to all our departmental colleagues of ICMR-VCRC Field station (erstwhile ICMR-CRME), Madurai.

\section{REFERENCES}

Arthur, D.R. 1962. Ticks and disease. Pergamon Press, Oxford, UK, $445 \mathrm{pp}$.

Bandaranayaka, K.O., Apanaskevich, D.A. and Rajakaruna, R.S. 2016. Life cycle of Amblyomma integrum (Acari: Ixodidae) under laboratory conditions. Experimental and Applied Acarology, 69: 335-345.

doi: 10.1007/s10493-016-0034-5

Barandika, J.F., Hurtado, A., Garcia-Esteban, C., Gil, H., Escudero, R., Barral, M., Jado, I., Juste, R.A., Anda, P. and Garcia-Perez, A.L. 2007. Tick-borne zoonotic bacteria in wild and domestic small mammals in Northern Spain. Applied and Environmental Microbiology, 73 (19): 6166-6171.

doi: 10.1128/AEM.00590-07

Brites-Neto, J., Roncato Duarte, K.M. and Martins, T.F. 2015. Tick-borne infections in human and animal population worldwide. Veterinary World 8 (3):301315.

doi: 10.14202/vetworld.2015.301-315

Chhillar, S., Chhilar, J.S. and Kaur, H. 2014. Investigations on some hard ticks (Acari: Ixodidae) infesting domestic buffalo and cattle from Haryana, India. Journal of Entomology and Zoology Studies, 2: 99-104.

Chochlakis, D., Loannou, I., Papadopoulos, B., Tselentis, Y. and Psaroulaki, A. 2014. Rhipicephalus turanicus: from low numbers to complete establishment in Cyprus. Its possible role as a bridge vector. Parasites \& Vectors, 7: 8-11.

doi: 10.1186/1756-3305-7-S1-P11

Dantas-Torresa, F., Martins, T.F., Munoz-Lealb, S., Onofrio, V.C. and Barros-Battesti, D.M. 2019. Ticks (Ixodida: Argasidae, Ixodidae) of Brazil: Updated species checklist and taxonomic keys. Ticks and Tick-borne Diseases, 10 (6):1-45. doi: 10.1016/j.ttbdis.2019.06.012

Dhanda, V. and Ramachandrarao. T. 1964. A report on collection of ixodid ticks made in North East Fortier Agency India. Indian Journal of Medical Research, 52: 1139-1153.

Estrada-Pena, A. and Jongejan, F. 1999. Ticks feeding on humans: a review of records on human-biting Ixodoidea with special references to pathogen transmission. Experimental and Applied Acarology, 23: 685-715. doi: 10.1023/a:1006241108739

Gandhi, S., Dave, P., Patel, G.C., Khatri, H.J., Shah, N. and Mishra, U. 2011. An epidemiological investigation of a multisource outbreak of Congo Crimean Haemorrhagic 
fever (CCHF). Journal of Communicable Diseases, 43: 161-167.

Geevargheese, G. and Mishra, A.C. 2011. Haemaphysalis ticks of India. Elsevier, London, UK, 253 pp.

Geevarghese, G., Fernandes, S. and Kulkarani, S.M. 1997. A checklist of Indian ticks (Acari: Ixodidae). Indian Journal of Animal Science, 67: 566-574.

Geevarghese, G. and Dhanda, V. 1987. The Indian Hyalomma ticks (Ixodoidea: Ixodidae). Indian Council of Agricultural Research, New Delhi, India, 119 pp.

Ghosh, S., Azhahianambi, P. and Yadav, M.P. 2007. Upcoming and future strategies of tick control: a review. Journal of Vector Borne Diseases, 44: 79-89.

Guglielmone, A.A., Sánchez, M.E., Franco, L.G., Nava, S., Rueda, L.M. and Robbins, R.G. 2015. Hard ticks (Acari: Ixodida: Ixodidae). A non-profit open-access web portal for original descriptions of tick species (valid and invalid), dubious and uncertain names, and selected nomina nuda. Available http://rafaela.inta.gob.ar/nombresgarrapatas/ (Last accessed: 18 August 2020).

Jagannath, M.S., Muraleedharan, K. and Hiregoudar, L.S. 1979. Prevalence of ixodid ticks of cattle at Bangalore. Indian Journal of Animal Science, 49: 890-894.

Jagannath, M.S. and Lokesh, V.V. 1988. Incidence of ixodid ticks of sheep and goats in Kolar district. Indian Journal of Animal Sciences, 58: 72-76.

Kaul, H.N., Shetty, P.S., Ghalsasi, G.R. and Dhanda, V. 1990. Survey of ticks (Acarina: Ixodidae) for Crimean haemorrhagic fever virus activity in Jammu and Kashmir state, India. Indian Journal of Medical Sciences, 91: 5-8.

Kumar, K., Balakrishnan, N., Katayal, R. and Gill, K.S. 2002. Prevalence of ixodid ticks in Nilgiri district of Tamil Nadu State (India). Journal of Communicable Diseases, 34: 124-127.

Kumar, K., Sexena, V.K. and Lal, S. 2008. Prevalence of vectors of scrub typhus, plague and KFD in district Shimoga, Karnataka state, India. In: Vector borne diseases: Epidemiology and control. Tyagi, B.K. (Ed.). Scientific Publishers, Jodhpur, India, 205-211.

Latha, B.R., Aiyasami, S.S., Pattabiraman, G., Sivaraman, T. and Rajavelu, G. 2004. Seasonal activity of ticks on small ruminants in Tamil Nadu State, India. Tropical Animal Health and Production, 36: 121-133. doi: 10.1023/B:TROP.0000012108.42526.11

Liyanaarachchi, D.R., Rajakaruna, R.S., Dikkumbura, A.W. and Rajapakse, R.P.V.J. 2015. Ticks infesting wild and domestic animals and humans of Sri Lanka with new host records. Acta Tropica, 142: 64-70. doi: 10.1016/j.actatropica.2014.11.001

Mehta, D.R. 1937. Studies on typhus in the Simla hills part viii ectoparasites of rats and shrews with special ref- erence to their possible role in the transmission of typhus. Indian Journal of Medical Sciences, 25: 353-365.

Miranpuri, G.S. and Singh, J. 1978. Ticks and mites from domestic animals in Assam, India and their possible role in transmission of diseases. Indian Journal of Parasitology, 2: 11-14.

Parola, P. and Raoult, D. 2001. Ticks and tick borne bacterial diseases in humans: An emerging infectious threat. Clinical Infectious Diseases, 32: 897-928.

doi: $10.1086 / 319347$

Pattnaik, P. 2006. Kyasanur forest disease: an epidemiological view in India. Reviews in Medical Virology, 16: 151-165. doi: $10.1002 / r m v .495$

Prakasan, K. and Ramani, N. 2007. Tick parasites of domestic animals of Kerala, South India. Asian Journal of Animal and Veterinary Advances, 2: 74-80. doi: 10.3923/ajava.2007.74.80

Saxena, V.K., Kaushal, K. and Rajagopal, R. 1984. Vertical distribution of ticks of domestic animals in Nilgiri hills (Tamil Nadu). Journal of Communicable Diseases, 16: 323-325.

Saxena, V.K. 1997. Ixodid ticks infesting rodents and sheep in diverse biotopes of South-India. Journal of Parasitology, 83: 766-767. doi: $10.2307 / 3284262$

Sen, P. 1938. A checklist and host list of Ixodidae (ticks) occurring in India. Indian Journal of Veterinary Science Animal Husbandary, 8: 133-149.

Shanmugam, J., Smirnova, S.E. and Chumakov, M. P. 1976. Presence of antibody to arboviruses of the Crimean Haemorrhagic Fever Congo (CHF Congo) group in human beings and domestic animals in India. Indian Journal of Medical Research, 64: 1403-1413.

Sharrif, M. 1928. A revision of Indian Ixodidae with special reference to the collections in the Indian Museum. Records of the Indian Museum, 30: 217-344.

Shobana, G., Gunasekaran, C. and Lena, M. 2013. A survey on ticks parasites in domestic animals of Villupuram district, South India. Research Journal of Animal, Veterinary and Fishery Sciences, 1 (5): 21-23.

Ghosh, S. and Nagar, G. 2014. Problem of tick and tick borne disease in India with special emphasis progress in control research: a review. Journal of Vector Borne Diseases, 51: 259-270.

Tonetti, N., Berggoetz, M., Ruhle, C., Pretorius, A.M. and Gern, L. 2009. Ticks and tick-borne pathogens from wildlife in the Free State province. South Africa. Journal of Wildlife Diseases, 45 (2): 437-446. doi: 10.7589/0090-3558-45.2.437

Varma, R.N. and Mahadevan, B. 1970. Ixodid ticks collected in the Eastern Himalayas and their potential dis- 
ease relationships. Indian Journal of Medical Science, 58 (6): 693-706.

Walker, A.R., Bouattour, A., Camicas, J.L., Estrada-Pena, A., Horak, I.G., Latif, A.A., Pegram, R.G. and Preston, P.M. 2003. Ticks of domestic animals in Africa: a guide to identification of species. Bioscience Reports, Edinburgh Scotland, UK, $221 \mathrm{pp}$.

Edited by: Salih Doğan

Reviewed by: Three anonymous referees

Citation: Ranganathan, K., Renu, G., Ayyanar, E., Veeramano-Haran, R. and Paulraj, P.S. 2021. Species composition of hard ticks (Acari: Ixodidae) on domestic animals and their public health importance in Tamil Nadu, South India. Acarological Studies, 3 (1): 16-21. 